\title{
КЛАСТЕР КАК МЕТОД ЭФФЕКТИВНОГО УПРАВЛЕНИЯ
}

\author{
(c) 2021 Сафиуллин Ленар Наилевич \\ доктор экономических наук, профессор \\ Центр перспективных экономических исследований Академии наук республики Татарстан, \\ Россия, Казань \\ E-mail: lenar_s@mail.ru \\ (c) 2021 Гулиев Эмин Анвар-Оглы \\ Азербайджанский университет туризма и менеджмента, Азербайджан, Баку \\ E-mail: eminquliyev.1977@mail.ru
}

Современные экономические реалии требуют формирования конкурентных преимуществ в обеспечении непрерывности экономического развития. Теоретический и практический анализ подтверждает, что это может быть достигнуто путем реализации кластерной стратегии. Кластеры создают возможности для повышения потенциала своих субъектов, обеспечения их эффективной и качественной деятельности. А это, в свою очередь, напрямую влияет на повышение конкурентоспособности национальной экономики. Обеспечение непрерывности и конкурентоспособности деятельности хозяйствующих субъектов зависит от правильного определения их стратегий управления. Повышение устойчивости и эффективности деятельности участников кластера может быть достигнуто за счет повышения производительности труда и эффективности производства. При этом для предприятий, работающих в комфортной логистической среде, необходимость учета географической близости предприятий, координации совместной деятельность между ними и формирования партнерских отношений наряду с другими важными факторами повышают эффективность управления предприятиями.

Ключевые слова: локальные производственные системы, территориально-производственный кластер, инновационная деятельность, конкурентоспособность региона, кластерная политика.

В последние годы в мире реализуются различные концепции повышения конкурентоспособности экономических систем, являющиеся гарантами экономического роста. В качестве основной причины, обусловившей необходимость этого процесса, можно указать на заметную активность глобализации, развитие средств коммуникации, формирование сетевых структур. В основе формирования сетевых структур лежит стимулирование сотрудничества производителей, обеспечение взаимной заинтересованности и непрерывности деятельности. Производителей товаров, предприятия сферы услуг, потребителей и специализированных поставщиков вместе с объединенной региональной связью вокруг научно-образовательного центра можно рассматривать как сетевую организацию.

В развитых странах в повышении конкурентоспособности национальной экономики широко используется кластерная стратегия как основа сетевой организации. Фактически, основной причиной этого является снижение эффективности традиционных методов диверсификации.
В настоящее время мировая практика показывает, что пока лучшим способом модернизации экономики является кластеризация. Кластеризация - это региональная и национальная экономическая система, позволяющая повысить конкурентоспособность, ускорить инновационную деятельность, защитить от влияния глобализации и адекватно отвечать требованиям времени.

Кластеризация, как способ сетевой организации играет большую роль в создании факторов, обеспечивающих экономический рост. К таким фактором можно отнести: кластерный сбор высококвалифицированных кадров, знаний, ноу-хау и опыта; увеличение инновационной деятельности субъектов предпринимательства за счет большей внутренней диффузии; проведение семинаров, тренингов для участников кластера; прозрачная передача информации об интенсивности и предпочтениях спроса; создание и совершенствование существующих и будущих методов решения проблем; развитие гибкости и скорости при внедрении инноваций; 
внедрение кластерной внутренней стандартизации по всем направлениям; минимизация затрат на приобретение и внедрение инноваций в результате международного сотрудничества; обеспечение развития предпринимательства путем создания спроса на товары и услуги; эффективность сетевого сотрудничества в привлечении иностранных инвестиций; выгодная маркетинговая возможность и расширение экспорта за счет экспортеров; разработка аутсорсинга при производстве продукции, работ и услуг между субъектами кластера и партнерами этих субъектов и т.д.

Объясняя причины конкурентоспособности концентрации малого и среднего предпринимательства в промышленных районах, А. Маршалл [6] отмечает, что группа малых и средних предприятий, сосредоточенных в одном районе страны и специализирующихся на выполнении определенных функций в рамках единого производственного процесса, будет не менее эффективным, чем вертикально интегрированные крупные заводы.

А. Маршалл также отмечает, что близость небольших фирм друг к другу повышает их конкурентоспособность перед крупными компаниями. Именно такое скопление предприятий с точки зрения различных экономических факторов он назвал “ промышленными районами» [6].

А. Маршалл обращает внимание на 3 основных фактора, стимулирующих развитие производства в промышленном районе и создающих особый экономический климат и повышающих конкурентоспособность малых и средних предприятий: общий рынок квалифицированной рабочей силы; локальная торговля между фирмами; местное разделение труда.

В 1970-х годах теорию промышленных зон А. Маршалла возродил Дж. Бэкатти, разработавший теорию итальянских промышленных регионов, которая дала толчок формированию конкурентных преимуществ малого и среднего бизнеса. Промышленную зону он определял как «социально-территориальную общность, характеризующуюся активным участием как населения, так и предприятий». В отличие от промышленных городов, в этих регионах общества и фирмы, как правило, объединяются [1, С. 40].

Основные факторы, положительно влияющие на непрерывность и динамику функционирования кластера, эксперты Европейской комиссии делят на 6 этапов:
1. Формирование новых фирм основано на специальных знаниях и производственных навыках, применяемых в определенной области.

2. Создание поставщиков и сервисных фирм, а также специализированного рынка труда.

3. Создание новых вспомогательных предприятий.

4. Привлечение новых фирм, квалифицированной рабочей силы в кластеры, а также создание благоприятной среды для открытия новых местных компаний.

5. Создание активов нерыночных отношений, которые будут способствовать распространению информации, знаний и инноваций в кластере.

6. Деградация кластера в результате исчерпания внутреннего инновационного потенциала и его закрытости для внешних инноваций.

Основным показателем достижения участниками кластера поставленных целей является прибыль. Главным условием, обеспечивающим прибыль, эффективность и непрерывность деятельности предприятия, является эффективное управление $[2,4,8,9,16]$.

Существует ряд важных показателей, которые необходимо учитывать при измерении эффективности управления, которые в то же время влияют на непрерывность функционирования кластеров: повышение эффективности деятельности компаний; положительное влияние корпоративного управления на скорость бизнес-процессов; подотчетность менеджеров и маркетологов разных уровней; снижение рисков; подотчетность менеджеров и маркетологов разных уровней; снижение рисков; согласование интересов между участниками корпоративных отношений и др. [7, 11, 12].

Границы кластеров определяются взаимодополняемостью между важными областями. Кластеры иногда могут охватывать несколько регионов по всей стране, а иногда даже выходить за пределы государственных границ. Например, в США фармацевтический кластер находится в Филадельфии, Нью - Джерси и Пенсильвании, в то время как химический кластер проходит через немецкоязычную территорию Швейцарии.

В последние годы многие страны (Германия, Франция, Великобритания, Италия, Швеция, Финляндия, Ирландия, Польша, Словакия, Болгария и др.) применяют кластерный подход практически во всех сферах социально-эконо- 
мического развития, реализации и регулирования национальных инновационных программ. При этом используются различные формы стимулирования и финансирования, среди которых прямое финансирование деятельности малых и инновационных предприятий; предоставление беспроцентных кредитов; целевые дотации на НИОКР; создание фондов внедрения инноваций с учетом возможного коммерческого риска, бесплатное ведение делопроизводства по заказам отдельных изобретателей, бесплатные услуги патентных поверенных, снижение государственных пошлин на отдельных изобретателей и др. [6, 15, 16].

Итальянский институт статистики (ISTAT) дал такое определение промышленным районам: «Это социально-экономическая единица, в которой взаимодействуют члены общества и малые и средние предприятия, участвующие в производственном процессе в регионе.»[14, С. 209].

Для более точного определения влияния кластеров на эффективное управление хозяйствующими субъектами и обеспечение непрерывности их деятельности рассмотрим экономику Италии.

Италия обладает небольшими природными ресурсами, такими как месторождения железа, угля и нефти. Большая часть сырья и материалов, необходимых для производства, и более $80 \%$ энергии, используемой в стране, импортируются. Государственный институт промышленной реконструкции-холдинг, объединяющий более 150 предприятий, больше функционирует под руководством правительства. Он входит в топ-10 отраслевых экономических групп в мире [17]. От $80 \%$ до 97\% всей произведенной продукции идет на экспорт.

Италия с постиндустриальной смешанной экономической моделью и устойчивым развитием занимает четвертое место в рейтинге экономически развитых стран Евросоюза, а в мире в 2020-2021 годах - восьмое.

Если мы занимаемся реинжинирингом, то вспомним, что кластер-это организацион- ная форма предприятий, функционирующих как единое целое (иногда зависимое) на основе единой программы развития на определенной территории.

Италия входит в число крупнейших производителей и поставщиков на мировой рынок автомобилей, велосипедов и мопедов, тракторов, стиральных машин и холодильников, радиоэлектронной продукции, промышленного оборудования, стальных труб, пластмасс и химических волокон, автомобильных шин, а также готовой одежды и кожаной обуви, макаронных изделий, сыра, оливкового масла, вина, консервов из фруктов и помидоров.

В Италии насчитывается около 206 кластеров, охватывающих текстильную, обувную, косметическую, фармацевтическую, сантехническую, мебельную, туристическую и другие отрасли. Каждый из этих кластеров принес Италии мировую известность своей продукцией.

В таблице 1 и графике 1 , представленными ниже, показано количество кластеров и объем ВВП в Италии в разные периоды. Мы сравнили, и ясно видно, насколько важны кластеры для экономики Италии и эффективного управления экономикой.

Малые и средние предприятия, характерные для севера и центра Италии, но также обеспечивающие международную специализацию страны, производство и разделение труда, составляют основу промышленных комплексов и кластеров в этих районах. На регион с более чем 200 комплексами приходится 45\% промышленной рабочей силы Италии и более $40 \%$ ее экспорта. В зависимости от ассортимента продукции, производимой в этом регионе, $1 / 3$ или $2 / 3$ идет на экспорт. Например, в географическом регионе Прато насчитывается несколько тысяч предприятий с 85000 сотрудников. 65\% производимого здесь текстиля и готовой одежды идет на экспорт. В целом $11 \%$ экспорта страны приходится на предприятия, работающие в регионе. 410 предприятий Montebell, на которых работает 8800 человек, экспортируют 73\% своей обуви.

Таблица 1. Количество кластеров и их положение в мире в 2000-х и 2020-х годах

\begin{tabular}{|c|c|c|c|}
\hline & Годы & $\begin{array}{c}\text { Количество } \\
\text { кластеров }\end{array}$ & Рейтинг страны \\
\hline 1 & 2003 & 75 & 5 \\
\hline 2 & 2018 & 206 & 2 \\
\hline
\end{tabular}




\section{Объем ВВП Италии, млрд долларов}

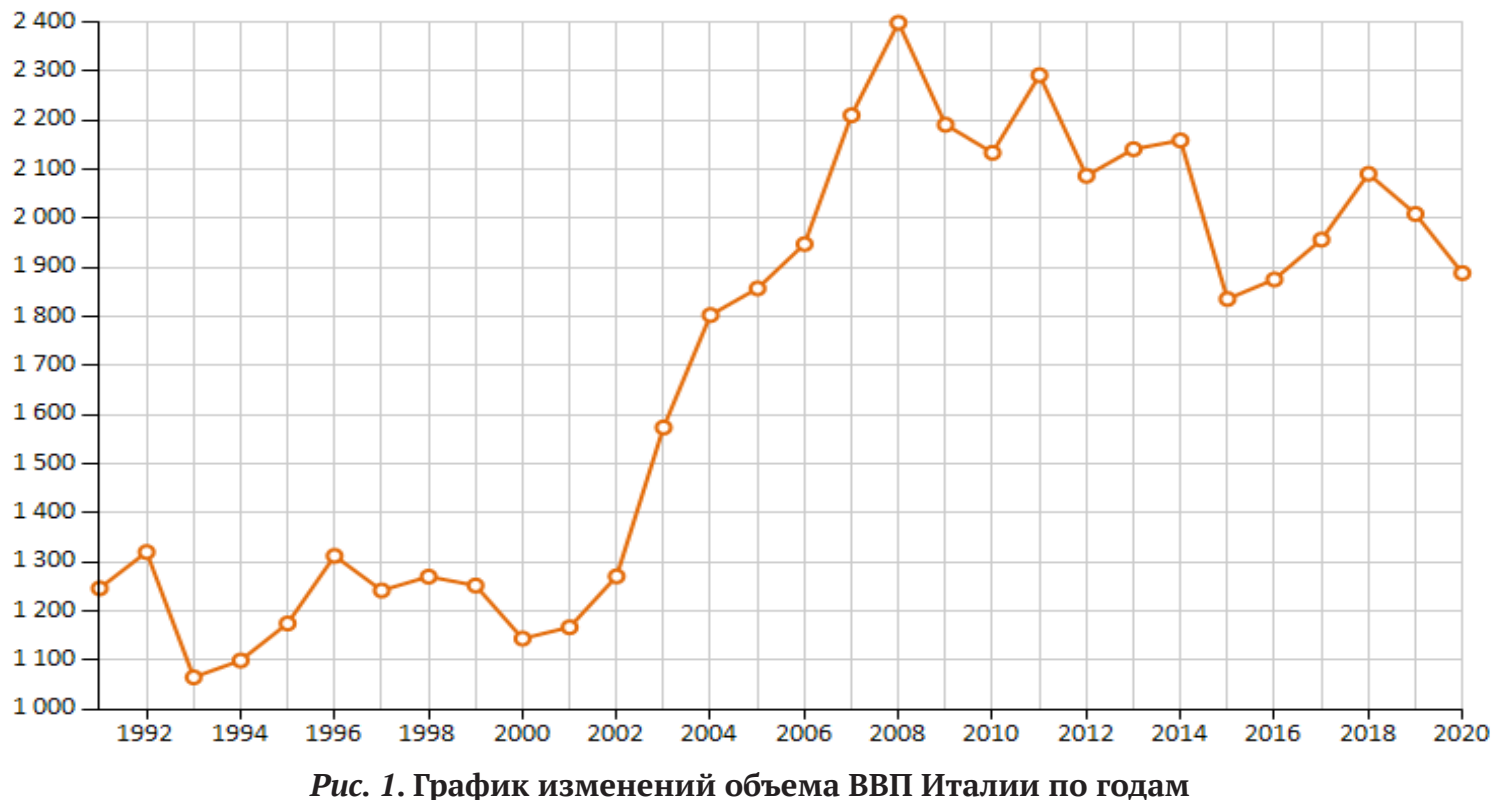

Благодаря производственному опыту, гибкому и динамичному потоку информации, человеческим ресурсам, устойчивым финансовым ресурсам и концентрации производственных мощностей удалось добиться обновления и диверсификации продукции на малых предприятиях. Согласно исследованию, проведенному Ко-

миссией ЕС, Италия лидирует по интенсивности этого процесса. Благодаря специфике инновационной модели Италии, удалось сохранить статус мирового поставщика не только многих видов товаров народного потребления, но и современного средне-технологического промышленного оборудования.

\section{Библиографический список}

1. Becattini G. The Marshallian industrial district as a socio-economic notion // Industrial districts and inter-firm cooperation in Italy; Edited by F. Pyke, G. Becattini, W. Sengenberger. - Geneva: ILO, 1991. - P. 37-51.

2. Fakhrutdinova E., Mokichev S., Kolesnikova J. THE INFLUENCE OF COOPERATIVE CONNECTIONS ON INNOVATION ACTIVITIES OF ENTERPRISES// World Applied Sciences Journal. 2013. T. 27. № 2. C. 212-215.

3. Дембич А.А., Закиева Л. Ф. Медицинские кластеры на территории МО г. Казань, как «точки роста» медицины региона // Известия КГАСУ. 2016. № 2 (36). С. 79-86. URL: https://cyberleninka.ru (дата обращения: 23.04.2020).

4. Захарова Е.Н., Ковалева И.П. Формирование медицинского кластера как направление интеграционного взаимодействия субъектов региональной медицинской сферы // Вестник Адыгейского государственного университета. 2013. № 4. С. 216-222. Режим доступа URL: https://cyberleninka.ru/свободный (дата обращения: 23.04.2020).

5. Кириенко О.Э., Киященко Т.А. Управление развитием рыночной инфраструктуры региона // Государственное и муниципальное управление. Ученые записки. 2019. С. 57-64. URL https://cyberleninka.ru (дата обращения: 18.02.2020)

6. Маршалл А. Принципы экономической науки. М.: Прогресс, 1993. 594 с. Режим доступа URL: http://www.library.fa.ru/files/Marshall свободный (дата обращения: 17.02.2020).

7. Мещерякова Ж.В. Медицинский кластер в системе здравоохранения региона как инновационная модель интеграции субъектов государственно-частного партнерства // Экономика и бизнес: теория и практика. 2017. № 3. C. 43-45. Режим доступа URL: https://www.semanticscholar.org/paper свободный (дата обращения: 25.04.2020).

8. Нестерова О.А., Гайзатуллин Р.P. Некоторые аспекты развития человеческого капитала в инновационной экономике // Экономические науки, 2021. - № 6. - С. 104-109. 
9. Нестерова О.А., Гайзатуллин Р.Р. Предпосылки к формированию концепции инноватора или инновационной личности и ее роли в экономике // Сборник научных статей по материалам Экономического форума с международным участием «Экономика в меняющемся мире», 2021. - С. 192-195.

10. Нестерова О.А. Особенности и противоречия формирования и развития инновационного человеческого потенциала // Казанский экономический вестник, 2021. - № 4.

11. Никитская Е.Ф., Пойкин А.Е. Концептуальные подходы к сущностной характеристике экономической и инновационной инфраструктуры // Вестник евразийской науки. 2016. T. 8, № 2. Режим доступа URL: https:// cyberleninka.ru свободный (дата обращения: 21.02.2020).

12. Орлов И.Ю., Багаутдинова Н.Г. К вопросу о направлениях пространственно-экономической трансформации региональной экономики // Казанский экономический вестник. 2016. № 3 (23). С. 18-21.

13. Семенова E.E., Анисимова В.Ю. Роль государства в создании рыночной инфраструктуры страны // Вестник Самарского университета. 2015. № 2. C. 144-147. URL: https://cyberleninka.ru/(дата обращения: 22.04.2020).

14. Соколенко С.И. Производственные системы глобализации: Сети. Альянсы. Партнерства. Кластеры: Украинский контекст. - К.: Логос, 2002. - 170 с.

15. Тонкова С., Бурматова О.П. Опыт Болгарии в формировании кластерной политики // Регион: экономика и социология. 2016. № 2. С. 237-252.

16. Фахрутдинова Е.В., Роднянский Д.В. Анализ энергетических кластеров и их влияния на социально-экономическое развитие регионов России// Экономические науки. 2016. № 142. С. 26-29.

17. Экономика Италии// Режим доступа URL: https://visasam.ru/emigration/economy/ekonomika-italii. html cвободный (дата обращения: 25.09.2021). 